\title{
Foaming in membrane bioreactors: Identification of the causes
}

\author{
Gaetano Di Bella ${ }^{\mathrm{a}, *}$, Michele Torregrossa ${ }^{\mathrm{b}}$ \\ ${ }^{a}$ Facoltà di Ingegneria, Architettura e delle Scienze Motorie dell'Università Kore di Enna, Cittadella Universitaria, 94100 Enna, Italy \\ bipartimento di Ingegneria Civile, Ambientale, Aerospaziale, dei Materiali, Università di Palermo, Viale delle Scienze, 90128 Palermo, Italy
}

\section{A R T I C L E I N F O}

\section{Article history:}

Received 23 November 2012

Received in revised form 8 May 2013

Accepted 15 May 2013

Available online 21 June 2013

\section{Keywords:}

EPS

Filamentous micro-organisms

Foam power

Foaming

MBR

Modified scum index

\begin{abstract}
A B S T R A C T
Membrane bioreactors (MBRs) represent by now a well established alternative for wastewater treatment. Their increasing development is undoubtedly related to the several advantages that such technology is able to guarantee. Nevertheless, this technology is not exempt from operational problems; among them the foaming still represents an "open challenge" of the MBR field, due to the high complexity of phenomenon. Unfortunately, very little work has been done on the foaming in MBRs and further studies are required. Actually, there is not a distinct difference between conventional activated system and MBR: the main difference is that the MBR plants can retain most Extracellular Polymeric Substances (EPSs) in the bioreactor. For these reason, unlike conventional activated sludge systems, MBRs have experienced foaming in the absence of foam-forming micro-organisms. Nevertheless, the actual mechanisms of EPS production and the role of bacteria in producing foam in activated sludge in MBRs are still unclear. In this paper, the authors investigated the roles of EPS and foam-forming filamentous bacteria by analyzing samples from different pilot plants using MBRs. In particular, in order to define the macroscopic features and the role of EPS and filamentous bacteria, a Modified Scum Index (MSI) test was applied and proposed. Based on the MSI and the foam power test, the causes of biological foaming were identified in terms of the potential for foaming, the quality and the quantity of the foam. The results indicated that the MBR foaming was influenced significantly by the concentration of bound EPSs in the sludge. In addition, the quantity and stability of MBR scum increased when both bound EPSs and foam-forming filamentous bacteria were present in the activated sludge.
\end{abstract}

() 2013 Elsevier Ltd. All rights reserved.

\section{Introduction}

An Membrane BioReactocr (MBR) system replaces the gravitational sedimentation unit of the conventional activated sludge (CAS) process and provides complete solid-liquid separation by the use of a microfiltration or an ultrafiltration membrane (Judd and Judd, 2010). The membrane allows the retention of all solids that are larger than 0.01 (Ultrafiltration)- 0.1 (Microfiltration) $\mu \mathrm{m}$, so free swimming bacteria are retained. Unfortunately, there are some disadvantages, such as membrane fouling and biological foaming (Di Bella et al., 2010; Mannina and Di Bella, 2012). In fact, the tank in which the membrane module is submerged may become a "foam trap" and the recirculation of trapped foam make foaming worse (Wanner, 1994; Jenkins et al., 2004).

The ability of some micro-organisms to float and create foam is well known in general microbiology. In particular, the biological

\footnotetext{
* Corresponding author. Tel.: +39 3313394288 (mobile); fax: +39 0935536623.

E-mail addresses: gaetano.dibella@unikore.it (G. Di Bella), michele.torrregrossa@ unipa.it (M. Torregrossa).
}

foaming by Nocardioform and Microthrix parvicella has been reported predominantly in nutrient removal plants that have different cultivation conditions compared with the conventional activated sludge plant (Wanner, 1994). In general, the periodic formation of foam, worries constantly the operators of wastewater treatment plant.

Although the phenomenon of foaming in CAS systems has been studied extensively, this is not the case for advanced wastewater treatment systems, such as membrane bioreactors (MBRs). Thus, the exact mechanism by which foam is formed and how to stabilise this process in MBRs has not been determined, and it may include several steps. Until this mechanism is determined, we will not be able to develop reliable control methods.

In general, foam results in the same adverse effects in both the CAS process and the MBR process, as described below:

- since significant quantities of mixed liquor suspended solids (MLSS) trapped inside the foam, it may be difficult to control the concentration of the sludge in the aeration tank;

- in warm climates, the foam decays rapidly, producing a foul odor; 
- if the production of foam is not curtailed, the foam can accumulate to such an extent that it can overflow the basin freeboard, covering walkways, handrails, surrounding areas, and creating hazardous or slippery conditions.

The investigation of foaming in the activated sludge process involves determining the propensity of mixed-liquor samples to foam and evaluating the various physico-chemical properties of the sludge that have been linked to CAS foaming in earlier studies (Fryer and Gray, 2012). In this context, the microscopic examination of activated sludge in many cases has shown that biological foams are generally enriched with gram-positive filamentous bacteria (Kragelund et al., 2007; Petrovski et al., 2011). Furthermore, the hydrophobic compounds that are synthesized and excreted by these bacteria increase the hydrophobicity of activated sludge, which is a key factor in controlling the formation of foam and stabilising the scum (Iwahori et al., 2001; Petrovski et al., 2011).

In the investigation of foaming in the activated sludge process, the usual approach is to conduct a series of foamability tests that simulate the aeration conditions in a plant and that provide an indication of the propensity of the sludge samples to generate foam. This approach is especially useful and important when new causes and effects must be identified, as is the case for the MBR process. Previously, simple foam tests were used to quantify the foam in CAS plants (Blackall et al., 1991; Constant, 1992; Pretorius and Laubscher, 1987). Similar foam tests have been used in recent years for MBR systems (Nakajima and Mishima, 2005; Di Bella et al., 2011). In particular, in order to define the quality, the quantity and the scum features, three main foam tests have been used: Scum Index (SI), Foam Rating (FR), Foam Power (FP). The SI quantifies the foam produced, in according with the selective flotation principle, proposed by Pretorius and Laubscher (1987), that provides a flotation of mixed liquor sample and a subsequent purification of separated scum from non-foam forming micro-organisms. The FR defines foam generation and stability in terms of foam volume, bubble size, foam speed formation and collapse time after aeration (Blackall et al., 1991).

The FP has been performed to evaluate the foam potential of MBR activated sludge, in according with protocol reported by Nakajima and Mishima (2005).

On the other hand, the surface areas covered by foam in different plants were determined for use in comparing the severity of foaming between plants (Hladikova et al., 2002), and, in some cases, foam coverage was found to correlate well with readings of foam potential (Torregrossa et al., 2005). Unfortunately, since the apparent degree of foam coverage on activated sludge tanks is likely to be influenced by the layout of the plant, the configuration of the process equipment, and operational parameters (e.g., trapping, recycling, and accumulation of foam in certain locations in the process), this variable must be used with extreme caution when compared on its own to other parameters, such as foam thickness and stability (Hug, 2006; Fryer and Gray, 2012).

Currently, none of the approaches reported in the international literature has presented a viable approach for quantifying the risk to MBR plants when foam forms the aeration surfaces. In fact, in the recent years, only a few experiments have been reported regarding the management and control of foaming in MBRs.

You and Sue (2009) investigated the role of certain microorganisms in the formation of foam in MBRs. Their study was related to the metabolism of particular micro-organisms, some of which were already known as "foam-forming" micro-organisms in CAS plants. However, foaming in the MBR process has attracted the attention of many researchers because, contrary to what happens in CAS plants, foam has been observed in MBR plants even in the absence of foam-forming micro-organisms (Nakajima and Mishima, 2005; Di Bella et al., 2011). Under these circumstances, it has been reported that the quantity of foam formed is related to the concentrations of extracellular polymer substances (EPSs) (Di Bella et al., 2011).

In general, however, there is not a distinct difference between CAS and MBR in terms of form-forming mechanisms. Some surfactants produced by foam-forming bacteria, EPS released by bacteria, and some other factors may be responsible for the production of biological foams in most of biological wastewater treatment systems. The main difference is that the MBR plants can retain most of EPSs in the system.

Bearing in mind such considerations, in the research reported in this paper, we investigated the roles of EPSs and of the abundance of foam-forming, filamentous bacteria by analysing samples from several MBR pilot plants. In particular, in order to define the macroscopic features of foam in MBRs and the role of EPS and filamentous bacteria in the formation of foam in MBRs, some test results reported by Di Bella et al. (2011) were used. Specifically, in order to quantify the foam produced and to differentiate the effects of EPS and filamentous bacteria, a "modified" scum index (MSI) test was proposed and used.

\section{Materials and methods}

\subsection{Experimental setup and operation}

Samples of mixed liquor were collected from three different MBR pilot plants that had different configurations. The characteristics of the influent wastewater and the operating conditions of each MBR plant are summarised in Table 1 . It is important to note that the values shown in the table are the average values that were measured during the experimental period (when the foam occurred in the pilot plant). Further, the plants have not been

Table 1

Wastewater characteristics and operating condition of investigated MBRs.

\begin{tabular}{|c|c|c|c|c|c|c|c|}
\hline \multicolumn{4}{|c|}{ Wastewater characteristics } & \multicolumn{4}{|l|}{ Operating condition } \\
\hline & MBR1 & MBR2 & MBR3 & & MBR1 & MBR2 & MBR3 \\
\hline $\mathrm{COD}_{\text {TOT }}(\mathrm{mg} / \mathrm{L})$ & 451 & 326.6 & 511.6 & Experimentation length (days) & 60 & 165 & 70 \\
\hline $\mathrm{COD}_{\mathrm{SOL}}(\mathrm{mg} / \mathrm{L})$ & 204 & 104 & 210 & Recirculation ratio/feed rate & $5: 1$ & $6: 1$ & $6: 1$ \\
\hline $\mathrm{BOD}_{5}(\mathrm{mg} / \mathrm{L})$ & 240 & 175.9 & 265 & Permeate flux $\left(\mathrm{L} / \mathrm{m}^{2} \mathrm{~h}\right)$ & 45 & 21 & 21 \\
\hline $\mathrm{NH}_{4}-\mathrm{N}(\mathrm{mg} / \mathrm{L})$ & 40.4 & 15.9 & 32.4 & HRT (h) & 13 & 18 & 18 \\
\hline $\mathrm{NO}_{\mathrm{x}}-\mathrm{N}(\mathrm{mg} / \mathrm{L})$ & 0.02 & 1.8 & 3.5 & SRT (days) & $\infty$ & 36 & $\infty$ \\
\hline TKN (mg/L) & - & 91.3 & 102.3 & $\mathrm{~F} / \mathrm{M}\left(\mathrm{kg}_{\mathrm{COD}} / \mathrm{kg}_{\mathrm{MLSS}}\right.$ day $)$ & $0.07-0.2$ & $0.06-0.19$ & $0.07-0.2$ \\
\hline $\mathrm{PO}_{4}-\mathrm{P}(\mathrm{mg} / \mathrm{L})$ & 1.4 & 1.5 & 2.1 & DO aerobic tank (mg/L) & 3.9 & 3.9 & 3.1 \\
\hline $\mathrm{P}_{\text {TOT }}(\mathrm{mg} / \mathrm{L})$ & - & 3.8 & 6.4 & Returned MLSS flow (L/h) & 90 & 120 & 120 \\
\hline TSS (mg/L) & 290 & 282.5 & 295 & Returned $\mathrm{NO}_{3}$ flow $(\mathrm{L} / \mathrm{h})$ & 225 & 240 & 240 \\
\hline VSS (mg/L) & 182 & 177.3 & 188 & MLSS (g/L) & $5.5-10.5$ & 5 & $6-8.2$ \\
\hline $\mathrm{T}\left({ }^{\circ} \mathrm{C}\right)$ & 19.8 & 20.8 & 23.6 & $\operatorname{MLSSV}(\mathrm{g} / \mathrm{L})$ & $3.5-7.5$ & 3.5 & $4.5-6.1$ \\
\hline $\mathrm{pH}$ & 7.5 & 7.6 & 7.7 & $\mathrm{Y}_{\mathrm{obs}}\left(\mathrm{g}_{\mathrm{CoD}} / \mathrm{g}_{\mathrm{vss}} \mathrm{rem}\right)$ & 0.18 & 0.07 & 0.12 \\
\hline
\end{tabular}


studied in parallel, but the experimental campaigns refer to different periods. In this context, the difference of the input parameters is attributable mainly to different dilution effects.

In general, the basic configuration of each plant was designed to remove biological nutrients. Particularly, the MBR1 plant consisted of a denitrification-nitrification scheme with a submerged plate membrane module, while the MBR2 and MBR3 plants had configurations that were adaptations of the University of Cape Town (UCT) process, in which a hollow membrane module is installed in a hybrid-submerged configuration (Zhang et al., 2009; Di Trapani et al., 2011; Cosenza et al., 2012). The difference between the MBR2 and MBR3 plants was the different values of sludge retention time (SRT) that were used during the experiments. The three pilot plants were built at the Acqua dei Corsari municipal wastewater treatment plant (WWTP) in Palermo, and municipal wastewater was used as the input to each plant. Initially, all three plants were inoculated with activated sludge that was collected directly from a full-scale WWTP. Samples of mixed liquor were collected from each of the pilot plants, and the samples were stored at ambient temperature and transported to the laboratory where they were analysed.

\subsection{Scum tests}

The use of the scum index (SI) to evaluate performance was inspired by the selective flotation principle proposed by Pretorius and Laubscher (1987) for the control of biological scum in the CAS processes. The flotation cell and the experimental station are shown in Fig. 1. In the original protocol established by Pretorius and Laubscher for the quantification of scum separation, samples of activated sludge were taken from the aeration tank. Specifically, in the tests, a 2-L aliquot was placed in the flotation cell and aerated at an intensity of $10 \mathrm{~L}_{\text {air }} \mathrm{L}^{-1} \mathrm{~h}^{-1}$ for 15 min, during which a thick, stable layer of scum formed. A rotameter was used to control and measure the flow rate of air. When the aeration was stopped and the scum layer had separated from the non-floating sludge, the sludge was withdrawn carefully through a drain pipe until only the scum layer remained. The flotation was repeated several times until all of the foam-forming microorganisms were transferred into the scum.

The separated scum was scraped and rinsed from the flotation cell and stored. Thus, the floating scum was placed in the flotation cell again and re-suspended with water until the total volume of the sample was 2 L. Subsequently, the "purification process" was performed under controlled aeration conditions for $15 \mathrm{~min}$. The process of re-suspension and purification was repeated, with steps of $15 \mathrm{~min}$, until the amount of foam formed was constant. This latter portion contained only the foam-forming biomass. The dry mass of recovered scum was determined, and the SI was defined as:

$\mathrm{SI}=\frac{\text { Mass of scum recovered }}{\text { Mass of SS initially present }} \cdot 100 \%$

Actually, the original method was modified slightly. In order to remove the non-scum forming, suspended micro-organisms (the

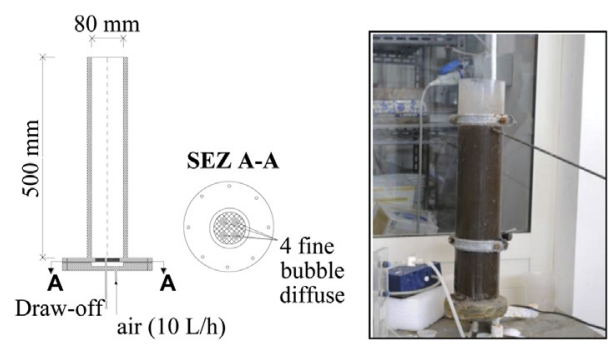

Fig. 1. Apparatus to determine SI (Pretorius and Laubscher, 1987). original SI procedure), the complete protocol was followed, with steps of 15-min aeration periods and subsequent purification of the separated scum. However, the results of each purification step in the step-by-step process, i.e., $\mathrm{SI}_{1}, \mathrm{SI}_{2}, \mathrm{SI}_{3} \ldots \mathrm{SI}_{n}$, were considered, as were the results of the flotation operation $\left(\mathrm{SI}_{0}\right)$. In fact, the dilution of the separated scum samples could have a negative influence on the original effect of EPS concentration. The logical scheme of the analytical protocol that was used to evaluate the different scum indices $\left(\mathrm{SI}_{\mathrm{X}}\right)$ is shown in Fig. 2.

The use of the concept of foaming rate (FR) was proposed initially by Blackall et al. (1991) in order to define the foaming ability of pure cultures obtained from activated sludge foams. In this work, the test was used to define the general quality of the foam in the activated sludge samples. The foaming apparatus used and the technique used to classify the foams are shown in Fig. 3. To determine the FR value, $50 \mathrm{~mL}$ of each activated sludge sample were poured into glass cylinders, and gas bubbles were forced through the air diffuser (pore size range of 40-90 $\mu \mathrm{m}$ ). The flow rate of the air was $200 \mathrm{~mL} \mathrm{~min}^{-1}$. The foam that was generated on the surface of the liquid was assessed. In particular, the generation of foam and its stability were evaluated in terms of the volume of the foam, the size of the bubbles, the speed of formation, and the time required for the foam to collapse after aeration was stopped (Blackall et al., 1991). The FR was rated on a scale of 0-7, where 0 represented the situation in which the mixed liquor was either unable to form scum or formed unstable foam, and 7 represents the situation in which the mixed liquor formed a dense and very stable foam.

The foam's quality was also calculated based on concepts used in food science (Kato et al., 1983; Constant, 1992). Specifically, in accordance with the measurement technique reported by Nakajima and Mishima (2005), the foam power (FP) test was performed to evaluate the potential for the activated sludge in an MBR to form foam and to evaluate the stability of such foam. FP was defined as the volume of the sample that was consumed for foaming $(\mathrm{mL})$ by $1 \mathrm{~L}$ of aeration. In particular, the $200-\mathrm{mL}$ samples were placed vertically in a transparent cylinder with a cross sectional area of $28 \mathrm{~cm}^{2}$. These tests were conducted with aeration periods $(\mathrm{T})$ of $30 \mathrm{~s}$ with an air flow $\left(\mathrm{Q}_{\text {air }}\right.$ ) of $10 \mathrm{~L} \mathrm{~min}^{-1}$. The difference between the levels of the interface of the liquid sample and the foam before and after aeration was designated as $\mathrm{H}_{0}$. Then, the FP value was calculated as shown in equation (2):

$\mathrm{FP}=\frac{H_{0} \cdot A}{\mathrm{Q}_{\mathrm{air}} \cdot T}$

\subsection{Determination of the quantity of filamentous bacteria}

Microscopic observations were conducted to identify filamentous bacteria. The observations were made under phase contrast at $100 \times$ and $1000 \times$ magnifications. The abundance and the dominance of the filamentous micro-organisms were estimated using the criteria suggested by Jenkins et al. (2004), i.e., by means of microscopic observations conducted with a LEICA ${ }^{\circledR}$ phase contrast microscope (DM-LB-100) connected to a digital camera.

In the Eikelboom method, the scum was immobilized on slides prior to identifying its morphological and physiological characteristics, including branching, motility, shapes of the filaments, location, growth of attached epiphytic bacteria, sheath, cell septa, diameters of the filaments, lengths of the filaments, shapes of the cells, floc size, sulphur deposits, and Neisser and Gram staining.

The identification of filamentous micro-organisms was conducted by using the morphological, dichotomous key proposed by Jenkins et al. (2004). The abundance of filamentous microorganisms $(\mathrm{Ab})$ was evaluated using the subjective scoring of the 


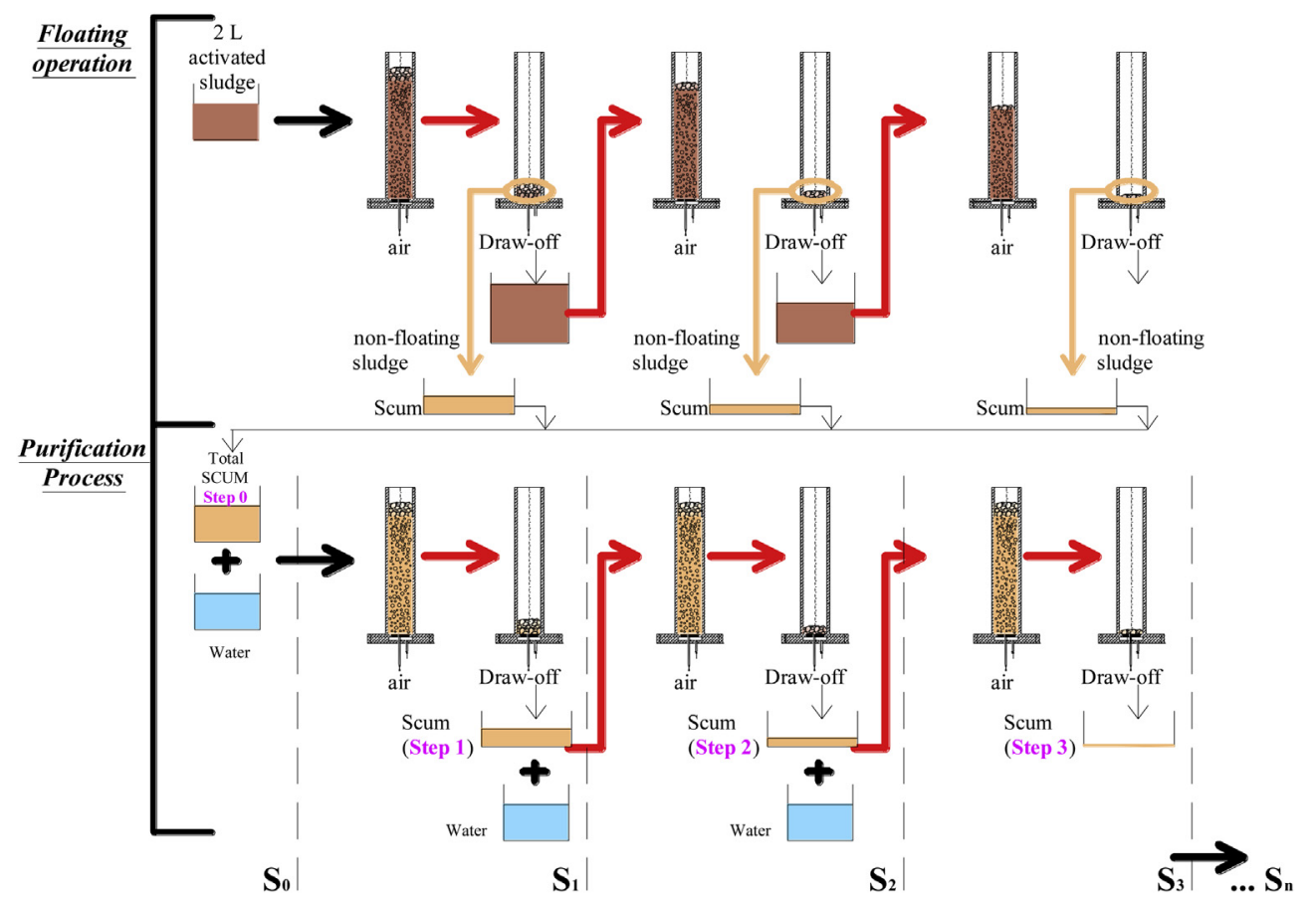

Fig. 2. Modified Scum Index procedure.

filaments, which allows the assignment of a numerical value to the presence of filaments on a scale from 0 to 6 (Jenkins et al., 2004).

The quantitative estimate of foam-forming microorganisms was calculated using the fast method originally proposed by Pitt and Jenkins (1990) to estimate the Nocardioform bacteria by extending it to all filamentous micro-organisms (Rossetti et al., 2006). After placing a volume of $50 \mu \mathrm{L}$ on the slide and staining the sample (Gram or Neisser) we could identify the probable number of filaments of a certain genus or type. This was done based on the proportion that existed between the number of intersections of a certain type of filaments detected in correspondence to three rectilinear tracks marked on the slide and the total amount of such filaments.

The average number of counted intersections, $\mathrm{X}_{\mathrm{avg}}$, was determined by counting the number of intersections on five slides and averaging the five numbers. Later, this average was related to the total mass of VSS in the sample ( $50 \mu \mathrm{L}$.VSS concentration in the mixed liquor), amplifying it in proportion to the number of fields of view covered by the sample at $1000 \times$ magnification (equivalent to 220 of view fields), as shown in Equation (3), which was used to calculate the normalized intersections number (NIN), as shown:

$\mathrm{NIN}=\frac{\mathrm{X}_{\mathrm{avg}} \cdot 220}{\mathrm{VSS} \cdot 50} \cdot 10^{6}$

where $10^{6}$ is the factor required to convert $\mu \mathrm{l}$ to $\mathrm{L}$.

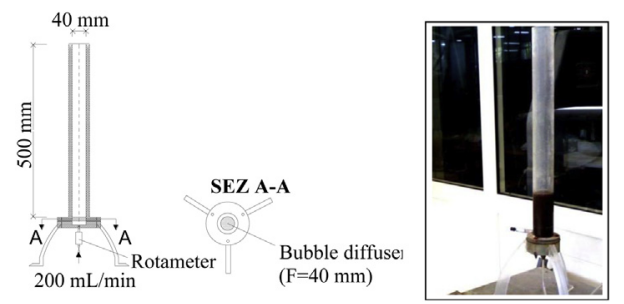

Fig. 3. Equipment for FR measurements (Blackall et al., 1991).

\subsection{Extraction and measurement of EPS}

In order to analyse the physiological condition of the biomass in the mixed liquor of the aerobic tank, the total concentration of extracellular polymeric substances $\left(\mathrm{EPS}_{\mathrm{T}}\right.$ ) was measured periodically. The concentration of $\mathrm{EPS}_{\mathrm{T}}$ was evaluated using the heating method (Zhang et al., 1999; Le Clech et al., 2006; Judd and Judd, 2010), the steps of which are described in Di Bella et al. (2011). Through this protocol, the soluble microbial products (SMPs), which represent the soluble portion of the EPS $\mathrm{T}$ and the bound EPS were measured.

The EPS $\mathrm{T}_{\mathrm{T}}$ matrix is very heterogeneous, and a variety of polymeric materials can be found within it, e.g., carbohydrates, proteins, lipids, and nucleic acids. Nevertheless, in this work, the sum of the contents of proteins and carbohydrates which are the dominant polymeric constituents was considered to be the EPS $\mathrm{T}$. In order to measure the contents of proteins and carbohydrates, the bound $\mathrm{EPS}_{\mathrm{T}}$ and the extracted SMPs were analysed using Lowry's method (Lowry et al., 1951) and Antrone's method (Dubois et al., 1956), respectively. Thus, the EPS ${ }_{\mathrm{T}}$ (both bound and soluble) were calculated as the sum of the two fractions, according to the following equation:

$E P S_{T}=\underbrace{E P S_{P}+E P S_{C}}_{E P S_{\text {Bound }}}+\underbrace{S M P_{P}+S M P_{C}}_{\text {Soluble EPS }}$

where the subscript symbols " $P$ " and " $C$ " indicate the relative content of proteins and carbohydrates in the EPS $\mathrm{T}_{\mathrm{T}}$ and SMP, respectively.

\subsection{Measurement of the volume of foam}

Foam Volume (FV) was calculated as the product of the area of the aerobic reactor that is covered by foam and the thickness of the foam. The area covered was measured daily with a perpendicular, photographic device joined to a digital-image elaboration system (Fig. 4). The area covered by foam was digitalised and measured 


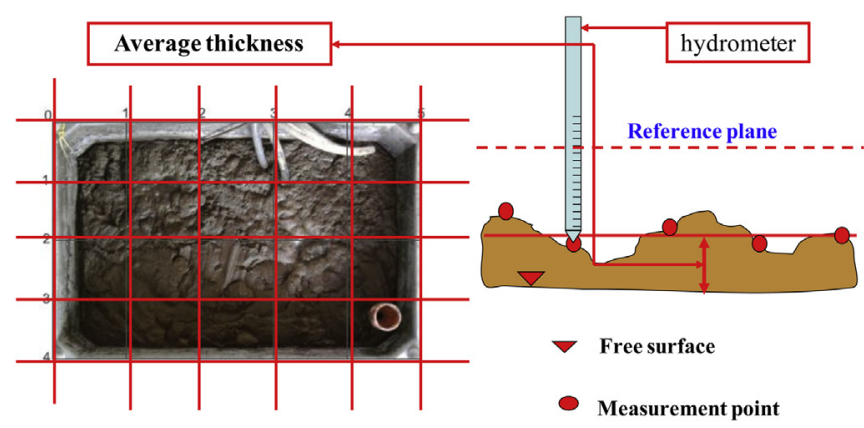

Fig. 4. Measurements of aerobic reactor area covered and thickness of the foam.

with CAD software. The mean thickness of the foam was measured with a hydrometer, and it was evaluated as the arithmetic mean of 12 measurements taken at different points on a fixed, horizontal grid.

It is important to emphasise that the FV may be influenced by the configuration of the pilot plant, as discussed earlier, so, consequently, it is not easy to repeat the measurement of FV. Thus, to make an objective analysis, the same aerobic tank was used in all three MBR plants (with the same area and the same total volume). In addition, the measures of FV were used only as a general assessment of the development and severity of this phenomenon.

\section{Results}

\subsection{General comment}

The foaming phenomenon occurred in all three plants. The general characteristics of the foam that formed are shown in Table 2, which reports the average values of the data measured during monitored period.

As shown in Table 2, even though foaming occurred in all three pilot plants, the foams had significant differences. Further, the foam in MBR2 appeared to be stable and dense $(F R=5)$. To the contrary, the foams in MBR1 and MBR3 were unstable (with mean FR values of 2 and 3, respectively), while the foam power of each of their mixed liquors was very high (about $70 \mathrm{~mL} \mathrm{~L}^{-1}$ in both pilot plants). Regarding the volume of the foam, there were no major differences in the estimated value of FV, and this confirms that the parameter represents a qualitative and general estimate of the foaming phenomenon; thus, it has very little utility for the characterization of such systems.

The differences in the types of foam were due predominantly to the different content of the EPS in the mixed liquor and to the difference in the amounts of filamentous bacteria. The highest concentrations of $\mathrm{EPS}_{\mathrm{T}}$ in activated sludge occurred in plants in which SRT $=\infty$, i.e., MBR1 and MBR3. Nevertheless, in MBR1, the foam-stabilizing bacteria were absent, while in MBR3 a small quantity of foam-forming and -stabilizing filamentous bacteria was found. This situation influenced the SI test significantly. In general, in the absence of filamentous bacteria, it was possible to run only the flotation step $\left(\mathrm{SI}_{0}\right)$. In fact, once that the foam was separated after the flotation phase, in the purification phase foam did not formed from the re-suspended sample, already after the step 1 , due to $\mathrm{EPS}_{\mathrm{T}}$ dilution.

In particular, regarding the analysis of foam-forming bacteria, the filamentous bacteria identified in the three MBRs were different. In general, no filamentous bacteria were observed in MBR1, while some foam-forming bacteria were identified in both MBR2 and MBR3. In particular, the Eikelboom type 0092 was the dominant foam-forming bacteria in MBR2 (average Ab equal 5) and E. type 1851 (average Ab equal 4) in MBR3. The other filamentous bacteria identified were E. type 0041 in MBR2, and E. type 0092 in both MBR2 and MBR3, both with $\mathrm{Ab}=2$.

According to previous observation, the MBR2 was the only one of the three pilot plants in which it was possible to apply the complete protocol of the SI test, starting with flotation $\left(\mathrm{SI}_{0}\right)$ and ending with purifying the foam in three separate steps $\left(\mathrm{SI}_{1}, \mathrm{SI}_{2}, \mathrm{SI}_{3}\right)$. Differently, in MBR3, which had a small quantity of foam-forming bacteria, the SI process continued until the first step of purification, and the values of $\mathrm{SI}_{0}$ and $\mathrm{SI}_{1}$ were measurable (only in five observations it was possible calculate also $\mathrm{SI}_{2}$ ). Contrarily, as discussed above, in the absence of filamentous bacteria, the foam of an MBR plant (i.e. MBR1) is unstable and influenced only by the concentration of $\mathrm{EPS}_{\mathrm{T}}$, confirming the results obtained in our previous studies (Di Bella et al., 2011).

Thus, when the biological matrix is diluted during the purification phase, the EPS $\mathrm{T}$ effect decreases while the effect of the filamentous bacteria increases, if they are present in the separated foam. This circumstance was confirmed in MBR2, where a greater amount of filamentous bacteria was observed.

\subsection{Role of the concentration of EPS in the formation of foam in MBRs}

First at all, it is important underlined that the main reason of the difference in EPSs concentration was due to the difference in wastewater characteristics, due to different dilution effects (see Table 1). Secondly, an influence is also due to the different SRT value, equal to 36 days in MBR2 and infinite in MBR1 and MBR3: therefore in agreement to the literature the average value in MBR2 was less than that in MBR1 and MBR3.

In this context, according to the previous observations, the roles of the concentration of EPS and the abundance of filamentous bacteria in the formation and quality of foam MBR plants were analysed. Specifically, the correlations between the concentrations of EPS $\mathrm{T}$ and the foaming test results are considered in this section. Initially, the correlation with SI was shown. The analyses that were conducted in all three pilot plants showed a good correlation with

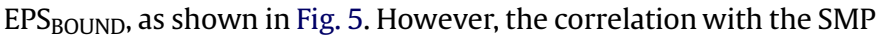
was not good.

As discussed above, the SI determinations were performed according to the characteristics of the activated sludge. In particular, the total absence of filamentous bacteria in MBR1 meant that we were able to conduct only the flotation phase, i.e., no steps were conducted in the purification phase. However, the correlation

Table 2

Foam characteristic of analyzed MBR.

\begin{tabular}{|c|c|c|c|c|c|c|c|c|c|c|}
\hline & $\mathrm{SI}_{0}$ & $\mathrm{SI}_{1}$ & $\mathrm{SI}_{2}$ & $\mathrm{SI}_{3}$ & FV & $\mathrm{FP}$ & FR & EPS $_{\text {Bound }}$ & SMP & Filamentous bacteria and their abundance (Ab) \\
\hline & $\%$ & $\%$ & $\%$ & $\%$ & $\mathrm{~L}$ & $\mathrm{~mL} / \mathrm{L}$ & $\mathrm{mg} / \mathrm{g}_{\mathrm{MLSS}}$ & $\mathrm{mL} / \mathrm{L}$ & & \\
\hline MBR1 & 12.18 & $<1$ & - & - & $4 \div 14$ & 72.45 & 2 & 54.03 & 1.57 & Absent \\
\hline MBR2 & 20 & 6.4 & 3.6 & 2.6 & $7 \div 17$ & 31.9 & 5 & 22.62 & 1.54 & E. type $0092(A b=5)$, E. Type $0041(A b=2)$ \\
\hline MBR3 & 7.81 & 2.8 & $<1$ & - & $6 \div 16$ & 70.62 & 3 & 121.16 & 10.2 & E. type $0092(A b=2)$, E. Type $1851(A b=4)$ \\
\hline
\end{tabular}



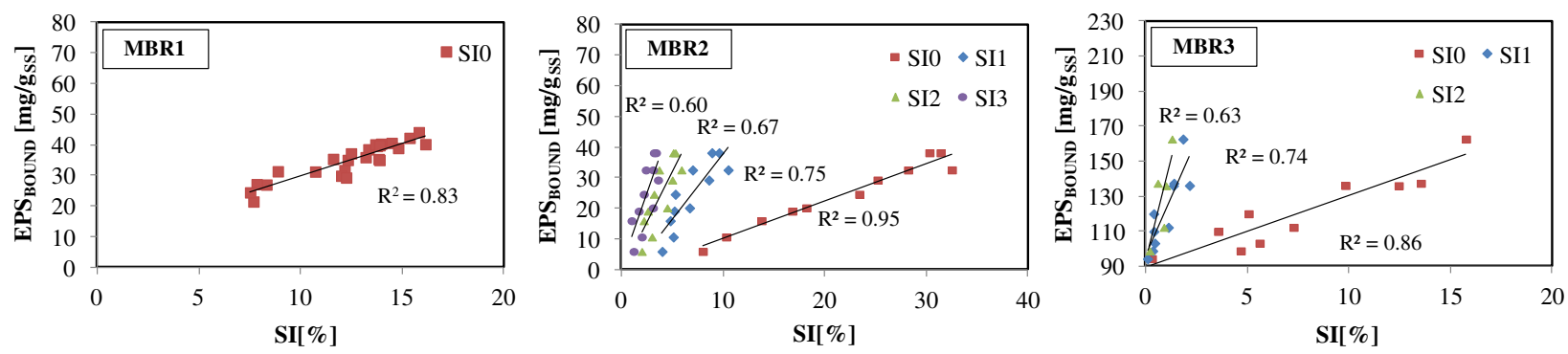

Fig. 5. Correlation between SI and $\mathrm{EPS}_{\mathrm{BOUND}}$ concentration.

between $\mathrm{EPS}_{\mathrm{BOUND}}$ and $\mathrm{SI}_{0}$ was very good according to Di Bella et al. (2011). This correlation was confirmed in MBR2 and MBR3. In these latter cases, as observed above, it was possible to perform the purification phase until the step 3 in MBR2 and until step 2 in MBR3. The difference in the advancement of the purification operation was due to the different quantities of foam-forming filamentous bacteria in the two pilot plants.

In general, the correlations between $\mathrm{EPS}_{\mathrm{T} / \mathrm{Bound}}$ and $\mathrm{SI}_{1}, \mathrm{SI}_{2}$, and $\mathrm{SI}_{3}$ were maintained, but they worsened at every step of the purification process. The previous correlations confirmed that the dilution of the separated scum sample had a negative influence

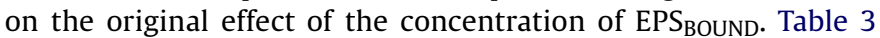
shows the $R^{2}$ and the slope factor (Sf) for each linear tendency correlation between $\mathrm{EPS}_{\mathrm{x}}$ and $\mathrm{SI}_{\mathrm{x}}$. In particular, in all three MBR pilot plants, the highest $\mathrm{Sf}$ were those of $\mathrm{ESP}_{\text {Bound,p }}$ and $\mathrm{SI}_{0}$ correlation.

Regarding the FP, the data confirm the good correlation between the foaming phenomenon and the concentration of EPS ${ }_{\text {BOUND. }}$

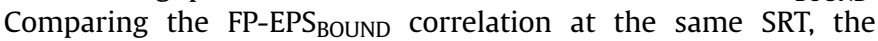
experimental analysis showed that foam power was related closely to the absolute value of the concentration of $\mathrm{EPS}_{\mathrm{BOUND}}$, as shown in

Table 3

Correlation index $\left(R^{2}\right)$ and slope coefficient $(\mathrm{Sf})$ for linear correlation between each EPS fraction and specific SI.

\begin{tabular}{|c|c|c|c|c|c|c|c|c|}
\hline & \multicolumn{2}{|l|}{$\mathrm{S}_{0}$} & \multicolumn{2}{|l|}{$\mathrm{S}_{1}$} & \multicolumn{2}{|l|}{$\mathrm{S}_{2}$} & \multicolumn{2}{|l|}{$\mathrm{S}_{3}$} \\
\hline & $\overline{R^{2}}$ & Sf & $\overline{R^{2}}$ & Sf & $\overline{R^{2}}$ & Sf & $\overline{R^{2}}$ & Sf \\
\hline \multicolumn{9}{|l|}{ MBR1 } \\
\hline $\mathrm{EPS}_{\mathrm{TOT}}$ & 0.53 & 2.64 & - & - & - & - & - & - \\
\hline $\mathrm{EPS}_{\text {BOUND }}$ & 0.83 & 2.1 & - & - & - & - & - & - \\
\hline $\mathrm{SMP}_{\mathrm{TOT}}$ & n.c. & - & - & - & - & - & - & - \\
\hline $\mathrm{EPS}_{\text {BOUND,C }}$ & 0.37 & 0.24 & - & - & - & - & - & - \\
\hline EPS $_{\text {BOUND,P }}$ & 0.86 & 1.86 & - & - & - & - & - & - \\
\hline $\mathrm{SMP}_{\text {TOT,P }}$ & - & - & - & - & - & - & - & - \\
\hline $\mathrm{SMP}_{\text {TOT,C }}$ & n.c. & - & - & - & - & - & - & - \\
\hline \multicolumn{9}{|l|}{ MBR2 } \\
\hline $\mathrm{EPS}_{\mathrm{TOT}}$ & 0.94 & 1.18 & 0.75 & 4.17 & 0.72 & 6.62 & 0.67 & 9.66 \\
\hline $\mathrm{EPS}_{\text {BOUND }}$ & 0.95 & 1.22 & 0.75 & 4.28 & 0.67 & 6.58 & 0.6 & 9.41 \\
\hline $\mathrm{SMP}_{\mathrm{TOT}}$ & n.c. & - & n.c. & - & n.c. & - & n.c. & - \\
\hline $\mathrm{EPS}_{\text {BOUND,C }}$ & 0.92 & 1.18 & 0.67 & 0.62 & 0.64 & 0.98 & 0.6 & 1.43 \\
\hline $\mathrm{EPS}_{\text {BOUND,P }}$ & 0.95 & 1.24 & 0.76 & 3.67 & 0.67 & 5.6 & 0.6 & 7.98 \\
\hline $\mathrm{SMP}_{\text {TOT,P }}$ & n.c. & - & n.c. & - & n.c. & - & n.c. & - \\
\hline $\mathrm{SMP}_{\text {TOT,C }}$ & n.c. & - & n.c. & - & n.c. & - & n.c. & - \\
\hline \multicolumn{9}{|l|}{ MBR3 } \\
\hline $\mathrm{EPS}_{\mathrm{TOT}}$ & 0.78 & 3.42 & 0.72 & 22.76 & 0.6 & 36.99 & - & - \\
\hline $\mathrm{EPS}_{\text {BOUND }}$ & 0.86 & 4.07 & 0.74 & 25.97 & 0.63 & 47.17 & - & - \\
\hline $\mathrm{SMP}_{\text {Tот }}$ & n.c. & - & n.c. & - & n.c. & - & - & - \\
\hline EPS $_{\text {BOUND,C }}$ & 0.9 & 0.56 & 0.73 & 3.49 & 0.71 & 6.41 & - & - \\
\hline EPS $_{\text {BOUND,P }}$ & 0.84 & 3.51 & 0.72 & 22.47 & 0.61 & 40.76 & - & - \\
\hline $\mathrm{SMP}_{\text {TOT,P }}$ & n.c. & - & n.c. & - & n.c. & - & - & - \\
\hline SMP $_{\text {Tот, }}$ & n.c. & - & n.c. & - & n.c. & - & - & - \\
\hline
\end{tabular}

- The test could not be performed.

n.c. correlation was not found.
Fig. 6, where the general correlation between $\mathrm{EPS}_{\text {BOUND }}$ and FP when SRT $=\infty$ (in MBR1 and MBR3) also is reported.

It is important to emphasise that, as was the case with SI, the specific correlations were influenced predominantly by the protein fraction rather than by the carbohydrate fraction.

\subsection{Role of filamentous bacteria in foaming in an $M B R$}

During the three experiments, as emphasised previously, foam formed only in plants MBR2 and MBR3 in which foam-forming filamentous microorganisms were identified. As shown in Table 2, the E. type 0092 and E. type 1851 are the morphotypes that dominated the biocenosis of biological foam in the examined cases even though they are considered "non-famous" scum bacteria (Lemmer et al., 2005). On the other hand, the quantities of other well-known, foam-forming bacteria, e.g., M. parvicella, Nocardioform, and Nostocoida limicola III were negligible.

The objective of investigation was to evaluate the influence of these micro-organisms on the formation of foam that also resulted from the strong influence of the EPS.

Consequently, the actual mechanisms and the bacteria responsible for foaming in activated sludge are still not clear. Nevertheless, it is important to note that You and Sue (2009) observed both E. types 0092 and 1851 bacteria in the activated sludge of an MBR in which foaming occurred. This may mean that, in the activated sludge of MBRs, the roles of some "non-famous" foam-forming bacteria may be different from their roles in conventional activated sludge systems.

Bearing in mind the previous discussion, significant correlations were detected between the SI value and the dominant, foam-forming filamentous bacteria that were identified, i.e., E. type 0092 and E. type 0041 in MBR2 and E. type 1851 and E. type 0092 in MBR3. Actually, in order to improve the analytical results, the normalized number of intersections, NIN, rather than the abundance $(\mathrm{Ab})$ parameter, was correlated with the EPS (because the classification does not continue as in the NIN classification). Furthermore, the total influence of all of the filamentous, foam-forming bacteria that were identified also was analysed. The correlations between NIN and SI are shown in Fig. 7. No significant correlations were found between FP and NIN.

Contrary to the previous SI-EPS $\mathrm{T}_{\mathrm{T} / \mathrm{BOUND}}$ correlations, the effect of foam-forming, filamentous bacteria increased with the advancement of the purification operation, and the correlations improved from $\mathrm{SI}_{0}$ to $\mathrm{SI}_{2}$ and $\mathrm{SI}_{3}$, as shown in Fig. 7. The improvement in the correlation was particularly significant after the flotation phase when the first step of the purification phase was conducted. The best correlation among those analysed was the correlation between the total number of intersections (considering all non-famous microorganisms) in each sample ( $\left.\mathrm{NIN}_{\mathrm{Tot}}\right)$ and the sum of all filamentous bacteria. Obviously, the correlation between $\mathrm{NIN}_{\mathrm{Tot}}-\mathrm{SI}_{\mathrm{X}}$ was 


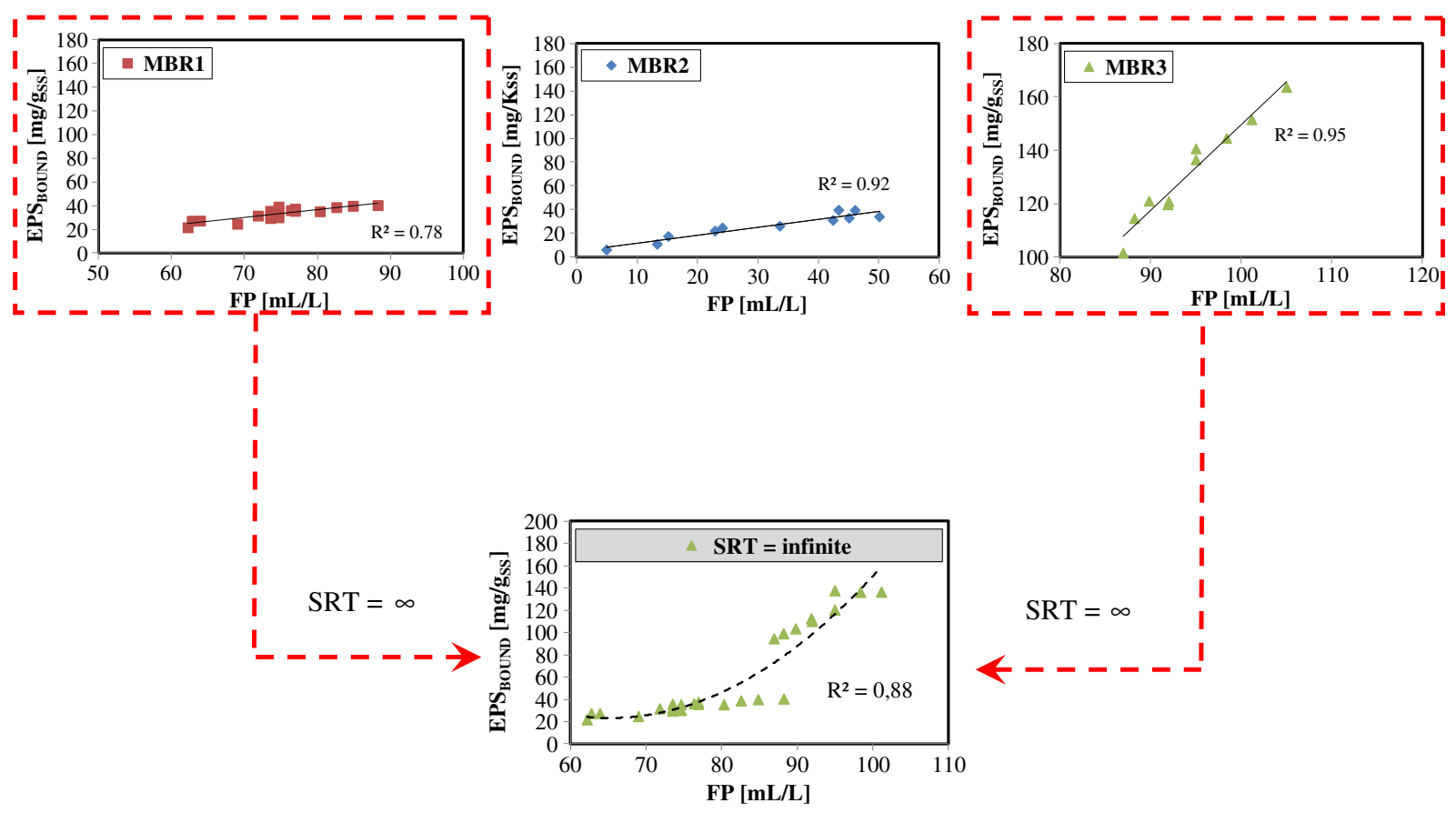

Fig. 6. Correlation between FP and $\mathrm{EPS}_{\text {Bound }}$ concentration.

influenced mainly by the presence of the dominant, foam-forming bacteria, i.e., E. type 0092 and type 1851 in MBR2 and MBR3, respectively.

The previous results confirm the observations of Pretorius and Laubscher in that they emphasise the importance of filamentous bacteria in the formation of foam, and, in the case of MBRs, some "non-famous" filamentous bacteria also were found to contribute to the formation of foam. Furthermore, coupling the results reported in Figs. 5 and 7 with the values of FR (Table 2), it seems apparent that the quality (stability and persistence) of foam in MBRs is characterized by the simultaneous presence of EPS $_{\text {BOUND }}$ and specific filamentous micro-organisms.

\subsection{Statistical analysis and the modified Scum Index}

In order to evaluate the contribution exerted by each element on the MBR foam formation, a statistical analysis has been carried out. It was performed by means of the multiple linear regression method. Indeed, the analysis was aimed at identifying a model which, starting from the knowledge of independent input variables, could be able to predict the value of the output variables (dependent). It is worth noting that all the considered variables are quantitative ones.

The analysis was firstly carried out independently for each pilot plant, since the available dataset was specific for each plant and it
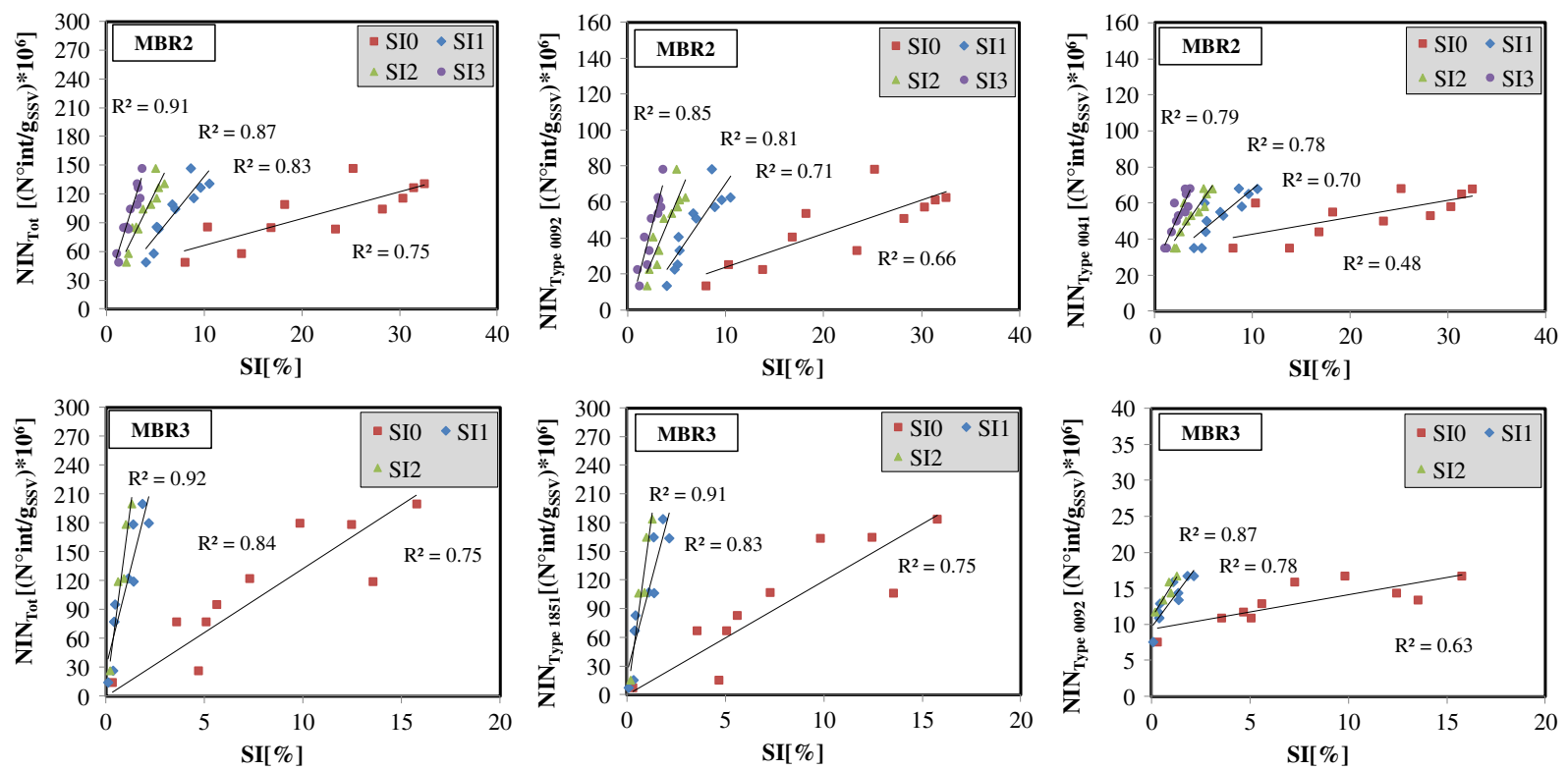

Fig. 7. Correlation between SI and normalized intersection number. 
was not possible to state if the overall model could be characterized by the same coefficients.

In order to meet this aim, it was firstly attempted to identify the mathematical model, for each plant as well as for each output variable, by means of the "step-wise regression" procedure, able on one hand to identify the parameters of interest in terms of output prediction, while, on the other hand, able to exclude that ones which give a negligible contribution.

After a first application of such a procedure, it was possible to identify the relationships shown in Table 4.

More in detail, the most significant relationships have been reported $(P$-value $<0.01)$, characterized by high values of the correlation coefficient $R^{2}$ as shown in Table 5. The other relationships, between NIN and FP for instance, showed a negligible correlation $(P$-value $>0.9)$.

At this point, it was possible to draw the following considerations:

1) referring to $\mathrm{FP}$ and $\mathrm{SI}_{0}$, the variables with high predictable capacity (evaluated on the basis of the rearranged $R^{2}$ value) are the $\mathrm{EPS}_{\text {bound }}$ (the carbohydrate fraction for the $\mathrm{SI}_{0}$ in particular), while, for $\mathrm{SI}_{1 / 2 / 3}$, when determined, the variable to take into account is the normalized number of observed filamentous (NIN).

2) to improve the prediction ability and to stabilize the model, the analysis was repeated, taking into account the total EPS bound, $_{\text {, }}$ (Table 5) state that the extracellular polymers bound to activated sludge flocs (both protein and carbohydrate) seem to be one of the most important factors for the potential foam formation (not foam stability).

The model resulted stable and with an increased predictive ability compared to the previous one. The suggestion is to choose

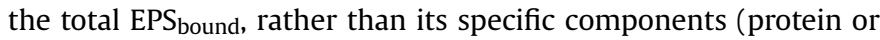
carbohydrate).

At this point it was aimed to evaluate if the models could be unified, not only in the structure, but in the coefficient values too. Actually, such situation was not possible, since the coefficient $R_{\mathrm{adj}}^{2}$ was always lower than $50 \%$ referred to the best influential parameter $\left(\mathrm{EPS}_{\mathrm{T}}\right)$. Therefore, the influence exerted by each original group (MBR1, MBR2, MBR3) is still significant, due to the specific operational conditions and different plant configurations.

Finally, it is possible to conclude that the EPSs exert a decisive role in foam formation as well as in its characteristics in MBR plants.

However, it is important to highlight that, among the evaluated indices, only the SI needs a more accurate investigation. Indeed, the original Foam Power test is able to exactly determinate the effect of $\mathrm{EPS}_{\mathrm{T}}$ only: the procedure proposed by Nakajima and Mishima (2005) is aimed at evaluating the "foaming power" on the basis of the direct effect of foaming due to chemicals (the EPS, referring to MBRs). On the contrary, referring to foam stability, besides the

Table 4

Step-wise regression analysis.

\begin{tabular}{llll}
\hline & Input & Output (main factor) & $R_{\text {adj }}^{2}$ \\
\hline MBR1 & $\mathrm{FP}$ & $\mathrm{EPS}_{\mathrm{C}}$ & 71.01 \\
& $\mathrm{SI}_{0}$ & $\mathrm{EPS}_{\mathrm{C}}$ & 79.79 \\
$\mathrm{FBR2}$ & $\mathrm{FP}$ & $\mathrm{EPS}_{\mathrm{C}}$ & 90.87 \\
& $\mathrm{SI}_{0}$ & $\mathrm{EPS}_{\mathrm{C}}$ & 94.86 \\
& $\mathrm{SI}_{1}$ & $\mathrm{NIN}$ & 81.99 \\
& $\mathrm{SI}_{2}$ & $\mathrm{NIN}$ & 86.61 \\
& $\mathrm{SI}_{3}$ & $\mathrm{NIN}$ & 84.75 \\
$\mathrm{MBR3}$ & $\mathrm{FP}$ & $\mathrm{EPS}_{\mathrm{P}}$ & 92.69 \\
& $\mathrm{SI}_{0}$ & $\mathrm{EPS}_{\mathrm{C}}$ & 89.04 \\
& $\mathrm{SI}_{1}$ & $\mathrm{NIN}$ & 82.21 \\
\hline
\end{tabular}

Table 5

Step-wise regression analysis for $\mathrm{EPS}_{\text {Bound. }}$.

\begin{tabular}{llll}
\hline & Output & Input (main factor) & $R_{\text {adj }}^{2}$ \\
\hline MBR1 & $\mathrm{FP}$ & $\mathrm{EPS}_{\text {Bound }}$ & 71.01 \\
& $\mathrm{SI}_{0}$ & $\mathrm{EPS}_{\text {Bound }}$ & 79.79 \\
$\mathrm{MBR} 2$ & $\mathrm{FP}$ & $\mathrm{EPS}_{\text {Bound }}$ & 90.87 \\
& $\mathrm{SI}_{0}$ & $\mathrm{EPS}_{\text {Bound }}$ & 94.86 \\
$\mathrm{MBR3}$ & $\mathrm{FP}$ & $\mathrm{ESS}_{\text {Bound }}$ & 92.69 \\
& $\mathrm{SI}_{0}$ & $\mathrm{EPS}_{\text {Bound }}$ & 89.04 \\
\hline
\end{tabular}

microscopic analysis of the bacterial species which are identified as foam stabilizing, the unique experimental field test, useful for plant management, is represented by the FR, which still remains a subjective analysis and thus foam evaluation is carried out on the basis of quality classes (from 0 to 7 ), without any quantitative characterization. Therefore, the SI can be defined as the most versatile test, despite the original protocol proposed by Pretorius was aimed at the quantification of the biological foam produced by filamentous foam-former bacteria.

In this context, it would be useful to propose a new index that could allow to evaluate also the EPS effect, by simply determining the foam separated step-by-step, due to the initial high EPS values (flotation and fist purification phases) and then taking into account the exclusive effect of filamentous bacteria (after the complete purification action). The basic idea is to evaluate the foaming effect due to EPS only $\left(\mathrm{SI}_{0}\right)$ and the other one due to bacteria only $\left(\mathrm{SI}_{n}\right)$, by passing through the several intermediate steps, which define the combined effect of EPS-filamentous bacteria $\left(\mathrm{SI}_{1}, \mathrm{SI}_{2}, \ldots\right)$.

In particular, the Modified Scum Index (MSI), which can easily be measured, was proposed as a means of quantifying risk on the basis of a new scum index protocol and interpretation. In particular, the probable effect of scum formation can be predicted and correlated with the concentration of $\mathrm{ESP}_{\mathrm{T}}$ in an aerobic plant and/or the presence of foaming-forming, filamentous bacteria. More specifically, it is important to note that the effect of EPS $S_{\mathrm{T}}$ was always present, since they were linked to the flocs, but the influence of the purification procedure decreased gradually. In this context, based on our on-site observations (surface areas covered by foam and the volume of the foam) and the characteristics of the foam (persistence and stability of the foam), we proposed a new classification of SI, as a function of each step of the flotation and purification phases. In particular, the organoleptic characteristics of the foam, i.e., colour, the sizes of the bubbles, the physical properties of the foam, and the properties of solid content in the scum, also were considered in order to define a shared classification.

The proposed MSI classification is shown in Table 6.

It should be noted that, different from the original classification of SI, the term "disastrous" was changed to "excessive." In fact, because no classification of settling tank management can be established, the critical conditions of MBR plant management that related to the development of foam were defined in accordance with the stresses of the system and, in particular, in the aeration tank and the membrane module (e.g., poor mixing and control of MLSS in the aerobic tank, overloading of the filtration system, and unpredictable fouling phenomena).

The simplicity of the proposed test is the fact that it requires limited equipment, which means that it can be considered as a good and favourable approach.

The MSI classification proposed is a quick and simple scale ranking system that was formulated specifically to quantify activated sludge foaming in MBRs. Obviously, other samples collected from full-scale MBR plants must be evaluated and compared in terms of the severity of foaming in order to standardize and use this method by making appropriate adjustments to the limits of each effect class. 
Table 6

Classification of Modified Scum Index.

\begin{tabular}{|c|c|c|c|c|c|c|c|}
\hline \multicolumn{2}{|c|}{ Effect of Scum before purification step } & \multicolumn{6}{|c|}{ Effect of Scum after purification step } \\
\hline & MSIO [\%] & & MSI1 [\%] & & MSI2 [\%] & & MSI3 [\%] \\
\hline Low & $0-10$ & Low & $0-10$ & Low & $0-7.5$ & Low & $0-5$ \\
\hline Moderate & $10-15$ & Moderate & $10-15$ & Moderate & $7.5-12.5$ & Moderate & $5-10$ \\
\hline Serious & $15-25$ & Serious & $15-20$ & Serious & $12.5-17.5$ & Serious & $10-15$ \\
\hline Excessive & $>25$ & Excessive & $>20$ & Excessive & $>17.5$ & Excessive & $>15$ \\
\hline
\end{tabular}

\section{Conclusions}

In this paper, we reported the results of the study of foaming in MBR plants. The foaming that occurred in three different MBR plants (working with different operational conditions and activated sludge characteristics) was compared. In order to study the phenomenon accurately, some foam tests that had been proposed in the past for use with CASs were investigated. In particular, the original procedure of the SI test was modified in order to consider the influence of the concentration of EPS (in addition to the influence of filamentous bacteria) on foaming in MBRs.

The results indicated that foaming in MBRs was influenced significantly by the concentration of bound EPS in the sludge, mainly the carbohydrate fraction. Further, when the presence of bound EPS was coupled with the presence and growth of foamforming, filamentous bacteria, the quantity and stability of the scum increased. Conversely, if the foam-forming bacteria were totally absent, the formation of foam depended exclusively on the concentrations of EPSs in the mixed liquor, which conditions the power of foaming but not its stability.

Finally, with regard to specific foam-stabilizing micro-organisms effect, it is important underline that, in a mixed cultures, the foam type differences cannot be completely explained and need new studies on it. In fact, we do not know exactly the full analysis of activated sludge mixed cultures with reference to foam producers and their differences, for each kind of foam. New studies for that unexplained subject are necessary in future works.

\section{References}

Blackall, L.L., Harbers, A.E., Greenfield, P.F., Haward, A.C., 1991. Activated sludge foams: effect of environmental variables on organism growth and foam formation. Environ. Technol. 12, 241-248.

Constant, M., 1992. A practical method for characterizing poured beer foam quality. J. Am. Soc. Brew. Chem. 50 (2), 37-47.

Cosenza, A., Di Bella, G., Mannina, G., Torregrossa, M., Viviani, G., 2013. Biological nutrient removal and fouling phenomena in a University of Cape Town Membrane Bioreactor treating high nitrogen loads. J. Environ. Eng. 139 (6), 773-780.

Di Bella, G., Durante, F., Torregrossa, M., Viviani, G., 2010. Start-up with or without inoculum? Analysis of a SMBR pilot plant. Desalination 260, 79-90.

Di Bella, G., Torregrossa, M., Viviani, G., 2011. The role of EPS concentration in MBR foaming: analysis of a submerged pilot plant. Bioresour. Technol. 102 (2), 16281635.

Di Trapani, D., Capodici, M., Cosenza, A., Di Bella, G., Mannina, G., Torregrossa, M. Viviani, G., 2011. Evaluation of biomass activity and wastewater characterization in a UCT-MBR pilot plant by means of respirometric techniques. Desalination 269, 190-197.
Dubois, M., Gilles, K.A., Hamilton, J.K., Rebers, P.A., Smith, F., 1956. Colorimetyric method for determination for sugars and related substances. Anal. Chem. 28, 350-356.

Fryer, M., Gray, N.F., 2012. Foaming scum index (FSI) e a new tool for the assessment and characterisation of biological mediated activated sludge foams. J. Environ. Manage. 110, 8-19.

Hladikova, K., Ruzickova, I., Klucova, P., Wanner, J., 2002. An investigation into studying of the activated sludge foaming potential by using physico-chemical parameters. Water Sci. Technol. 46, 525.

Hug, T., 2006. Characterization and Controlling of Foam and Scum in Activated Sludge Systems. Swiss Federal Institute of Technology Zurich, Switzerland. PhD thesis.

Iwahori, K., Tokutomi, T., Miyata, N., Fujita, M., 2001. Formation of stable foam by the cells and culture supernatant of Gordonia (Nocardia) amarae. J. Biosci. Bioeng. 92, 77-79.

Jenkins, D., Richard, M., Daigger, G., 2004. Manual on the Causes and Control of Activated Sludge Bulking, Foaming, and Other Solids Separation Problems, third ed. IWA Publishing, London, UK, pp. 132-147.

Judd, S.J., Judd, C., 2010. The MBR Book - Second Edition: Principles and Applications of Membrane Bioreactors in Water and Wastewater Treatment. Elsevier, London, UK.

Kato, A., Takahashi, A., Matsudomi, N., Kobayashi, K., 1983. Determination of foaming properties of proteins by conductivity measurements. J. Food Sci. 48, 62-65.

Kragelund, C., Remesova, Z., Nielsen, J.L., Thomsen, T.R., Eales, K., Seviour, R., Wanner, J., Nielsen, P.H., 2007. Ecophysiology of mycolic acid containing Actinobacteria (Mycolata) in activated sludge foams. FEMS Microbiol. Ecol. 61, 174-184.

Le-Clech, P., Chen, V., Fane, T.A.G., 2006. Fouling in membrane bioreactors used in wastewater treatment. J. Mem. Sci. 284, 17-53.

Lemmer, H., Lind, G., Müller, E., Schade, M., 2005. Non-famous scum bacteria: biological characterization and Troubleshooting. Acta Hydrochi. Hydrobio. 33, 197-202.

Lowry, O.H., Rosebrough, N.J., Farr, A.L., Randall, R.J., 1951. Protein measurement with Folin phenol reagent. J. Biol. Chem. 193, 265-275.

Mannina, G., Di Bella, G., 2012. Comparing two start-up strategies for MBRs: experimental study and mathematical modelling. Biochem. Eng. J. 68, 91-103.

Nakajima, J., Mishima, I., 2005. Measurement of foam quality of activated sludge in MBR process. Acta Hydrochi. Hydrobio. 33, 232-239.

Petrovski, S., Dyson, Z.A., Quill, E.S., Mcilroy, S.J., Tillett, D., Seviour, R.J., 2011. An examination of the mechanisms for stable foam formation in activated sludge systems. Water Res. 45, 2146-2154.

Pitt, P.A., Jenkins, D., 1990. Causes and control of Nocardia in activated sludge. Res. J. Water Pollut. Control Fed. 62, 143-150.

Pretorius, W.A., Laubscher, C.P., 1987. Control of biological scum in activated sludge plant by mean of selective floating. Water Sci. Technol. 19, 1003-1011.

Rossetti, S., Blackall, L.L., Tandoi, V., 2006. The microbiology of activated sludge process. In: Tandoi, V., Jenkins, D., Wanner, J. (Eds.), “Theory, Control Measures, Practical Experience" - IWA Specialist Group on Activates Sludge Population Dynamics. IWA Publishing, pp. 11-34.

Torregrossa, M., Viviani, G., Vinci, V., 2005. Foaming estimation tests in activated sludge systems. Acta Hydrochi. Hydrobio. 33, 240-246.

Wanner, J., 1994. Activated Sludge Bulking and Foaming Control. Technomic publication AG, Lancaster, Pennsylvania (USA).

You, S.J., Sue, W.M., 2009. Filamentous bacteria in a foaming membrane 4 bioreactor. J. Memb. Sci. 342, 42-49.

Zhang, X.Q., Bishop, P.L., Kinkle, B.K., 1999. Comparison of extraction methods for quantifying extracellular polymers in biofilms. Water Sci. Technol. 39, 211-218.

Zhang, H., Wang, X., Xiao, J., Yang, F., Zhang, J., 2009. Enhanced biological nutrient removal using MUCT-MBR system. Bioresour. Technol. 100, 1048-1054. 